\title{
Pharmacokinetics, Safety, and Efficacy of Intravitreal Digoxin in Preclinical Models for Retinoblastoma
}

\author{
Ursula Winter, ${ }^{1,2}$ Emiliano Buitrago, ${ }^{1}$ Hebe A. Mena,${ }^{3}$ Maria José Del Sole, ${ }^{4}$ Viviana Laurent,${ }^{1}$ \\ Soledad Negrotto, ${ }^{2,3}$ Jasmine Francis, ${ }^{5}$ Eloisa Arana, ${ }^{6}$ Mariana Sgroi, ${ }^{7}$ Juan O. Croxatto, ${ }^{2,8}$ \\ Hakim Djaballah, ${ }^{9}$ Guillermo L. Chantada, ${ }^{10}$ David Abramson, ${ }^{5}$ and Paula Schaiquevich ${ }^{1,2}$
}

\author{
${ }^{1}$ Clinical Pharmacokinetics Unit, Hospital de Pediatría J.P. Garrahan, Ciudad Autonoma de Buenos Aires (CABA), Buenos Aires, \\ Argentina \\ ${ }^{2}$ Consejo Nacional de Investigaciones Cientificas y Tecnicas, Consejo Nacional de Investigaciones Científicas y Técnicas \\ (CONICET), CABA, Buenos Aires, Argentina \\ ${ }^{3}$ Experimental Thrombosis Laboratory, Instituto de Medicina Experimental (IMEX), National Academy of Medicine, CABA, Buenos \\ Aires, Argentina \\ ${ }^{4}$ Pharmacology Laboratory, Faculty of Veterinary, National University of the Center of Buenos Aires, Tandil, Buenos Aires, Argentina \\ ${ }^{5}$ Ophthalmic Oncology Service, Memorial Sloan-Kettering Cancer Center, New York, New York, United States \\ ${ }^{6}$ Inmunogenetics Laboratory, Instituto de Inmunologia, Genetica y Metabolismo (INIGEM), University of Buenos Aires, CABA, \\ Buenos Aires, Argentina \\ ${ }^{7}$ Service of Ophthalmology, Hospital de Pediatría J.P. Garrahan, CABA, Buenos Aires, Argentina \\ ${ }^{8}$ Argentinean Foundation of Ophthalmology Jorge Malbrán, CABA, Buenos Aires, Argentina \\ ${ }^{9}$ High-Throughput Drug Screening Facility (HTS) Core Facility Memorial Sloan-Kettering Cancer Center, New York, New York, \\ United States \\ ${ }^{10}$ Service of Hematology-Oncology, Hospital de Pediatría JP Garrahan, CABA, Buenos Aires, Argentina
}

Correspondence: Paula Schaiquevich, Clinical Pharmacokinetics Unit, Hospital de Pediatría J.P. Garrahan, Combate de los Pozos 1881, C1245AAL, Buenos Aires, Argentina; paulas@conicet.gov.ar.

Submitted: December 10, 2014 Accepted: May 6, 2015

Citation: Winter U, Buitrago E, Mena HA, et al. Pharmacokinetics, safety, and efficacy of intravitreal digoxin in preclinical models for retinoblastoma. Invest Ophthalmol Vis Sci. 2015;56:4382-4393. DOI:10.1167/ iovs.14-16239
Purpose. To assess in vitro cytotoxic activity and antiangiogenic effect, ocular and systemic disposition, and toxicity of digoxin in rabbits after intravitreal injection as a potential candidate for retinoblastoma treatment.

Methods. A panel of two retinoblastoma and three endothelial cell types were exposed to increasing concentrations of digoxin in a conventional (72-hour exposure) and metronomic (daily exposure) treatment scheme. Cytotoxicity was defined as the digoxin concentration that killed 50\% of the cells (IC50) and was assessed with a vital dye in all cell types. Induction of apoptosis and cell-cycle status were evaluated by flow cytometry after both treatment schemes. Ocular and systemic disposition after intravitreal injection as well as toxicity was assessed in rabbits. Electroretinograms (ERGs) were recorded before and after digoxin doses and histopathological examinations were performed after enucleation.

Results. Digoxin was cytotoxic to retinoblastoma and endothelial cells under conventional and metronomic treatment. IC50 was comparable between both schedules and induced apoptosis in all cell lines. Calculated vitreous digoxin $C_{\max }$ was $8.5 \mu \mathrm{g} / \mathrm{mL}$ and the levels remained above the IC50 for at least 24 hours after intravitreal injection. Plasma digoxin concentration was below $0.5 \mathrm{ng} / \mathrm{ml}$. Retinal toxicity was evident after the third intravitreal dose with considerable changes in the ERG and histologic damage to the retina.

Conclusions. Digoxin has antitumor activity for retinoblastoma while exerting antiangiogenic activity in vitro at similar concentrations. Metronomic treatment showed no advantage in terms of dose for cytotoxic effect. Four biweekly injections of digoxin led to local toxicity to the retina but no systemic toxicity in rabbits.

Keywords: digoxin, pharmacokinetics, cytotoxicity, retinoblastoma, antiangiogenic, cancer
$\mathrm{D}$ espite recent advances in the local routes for chemotherapy delivery, few agents have been incorporated in the chemotherapy armamentarium for retinoblastoma treatment. ${ }^{1-3}$ Vitreous seeding of the tumor remains the more important obstacle to cure. Intravitreal injection of chemotherapeutic drugs became a critical tool for the successful treatment of vitreous seeds. ${ }^{2,3}$ Melphalan is the most commonly used chemotherapy agent for intravitreal injection, but its retinal toxicity is dose-limiting and new agents for intravitreal use that could act by a different mechanism are needed. ${ }^{4}$ Using a high-throughput screening approach, Antczak et al. ${ }^{5}$ identified cardenolides as active antiproliferative agents in human cell lines of ocular tumors and xenograft models of retinoblastoma. The in vitro antiproliferative activity of the cardenolides exceeded all of the currently available chemotherapeutic agents presently being used to treat retinoblastoma.

Among the cardenolides, digoxin is a positive inotropic agent used for congestive heart failure and atrial fibrillation. Several reports have shown in vitro cytotoxic effects in different cell lines as well as in adult cancer patients 
concomitantly treated with cardenolides (reviewed in Ref. 6). Many mechanisms have been proposed to explain the antitumor effect. ${ }^{6-9}$ Cardiac glycosides (and derivatives) were evaluated clinically in phase I studies in patients with breast cancer $^{10}$ but not yet in studies in pediatric patients with cancer.

The preferred route of digoxin administration in children with retinoblastoma would depend not only on its ability to reach the target tissues but also on possible systemic toxicity. Super-selective ophthalmic artery infusion (SSOAI) was used in one retinoblastoma patient with a measurable but not sustained clinical response. ${ }^{11}$ Although SSOAI led to 6-fold higher exposure in the vitreous compared with periocular injection of the same dose of topotecan in a swine model, the penetration of the drug into the vitreous depends on the physicochemical properties of the drug. ${ }^{12}$ Therefore, this may not be the preferred route for digoxin administration in retinoblastoma treatment. Additionally, digoxin has a narrow therapeutic range and well-known consequent cardiovascular toxicity, ${ }^{13}$ favoring intravitreous delivery because this route allows a 50-times higher exposure in the vitreous compared with the plasma of rabbits. ${ }^{14}$ In addition, since intravitreally implanted devices may be designed to achieve a sustained drug release that would be of interest for retinoblastoma, based on the antiangiogenic activity of cardenolides and that vessel density was previously related to the extent of tissue invasion in patients with retinoblastoma, we decided to evaluate the activity of digoxin as an antiangiogenic agent as an alternative strategy for inhibiting retinoblastoma. ${ }^{15-17}$ Metronomic delivery of chemotherapy is effective both in vitro and in vivo in different pediatric solid tumors. ${ }^{18-21}$ This treatment modality refers to the frequent and repetitive administration of the chemotherapeutic agent at relatively low doses compared with conventional chemotherapy without prolonged drug-free breaks between cycles. ${ }^{22-24}$ The main advantage involves avoiding acute severe adverse events because of the lower maximum plasma concentration and systemic exposure after each dose, while obtaining the same clinical outcome as after the maximum tolerated dose. ${ }^{22}$ Metronomic scheme targets not only tumor-associated vascular development but also has a direct cytotoxic effect on tumor cells and exerts some activity in the immune mechanisms for tumor control. ${ }^{22,23}$ In this study, we undertook a multimodal approach in order to evaluate in vitro and in vivo efficacy and safety of intravitreal digoxin as a potential candidate for retinoblastoma treatment based on:

1. In vitro cytotoxicity studies of digoxin to determine the inhibitory concentrations in two retinoblastoma cell lines;

2. In vitro cytotoxicity studies in three endothelial cell lines to assess the antiangiogenic effect of digoxin;

3. Comparison of the in vitro cytotoxic effect of digoxin in retinoblastoma and endothelial cells under two schedules, conventional and metronomic treatment;

4. In vivo pharmacokinetic characterization of digoxin in the vitreous and ocular tissues and plasma of rabbits after an intravitreal dose; and

5. Safety studies in rabbits after repetitive intravitreal doses.

\section{Methods}

\section{Cell Culture}

Y79 and WERI-RB1 cells were obtained from the American Type Culture Collection (Manassas, VA, USA). Cells were maintained in RPMI 1640 culture media (Invitrogen-Life Technologies, Rockville, MD, USA) with various supplements as previously described. ${ }^{25}$ Human umbilical vein endothelial cells (HUVEC) and late outgrowth endothelial progenitor cells (EPC) were obtained from umbilical cord vein and blood, respectively, after full-term deliveries. ${ }^{26}$ The institutional review board of the National Academy of Medicine, Argentina approved the protocol and informed consent was obtained from the mothers before collecting the cord blood. Human microvascular endothelial cells (HMEC-1) were obtained from the American Type Culture Collection. All endothelial cells were maintained in endothelial growth medium-2 (EGM2) from Lonza (Walkersville, MD, USA) with supplements as previously described. ${ }^{24}$

\section{Conventional and Metronomic Dosing of Digoxin}

Retinoblastoma and endothelial cell lines were incubated with digoxin for 72 hours using conventional treatment as well as low doses for longer periods of time (between 5 and 7 days) referred to as metronomic treatment.

To assess the effect of conventional dosing of digoxin, retinoblastoma cell lines (Y79 and WERI-RB1) were seeded in 96-well plates and allowed to grow for 24 hours. Subsequently, cells were exposed to eight different concentrations of digoxin (0.01-100 $\mu \mathrm{M})$ for 72 hours. Five independent assays were performed in triplicates for each concentration of digoxin. Digoxin IC50 was determined for each assay and thereafter the median (range) was calculated. For metronomic dosing of digoxin, cells were exposed to digoxin in a dose range as indicated $(0.001-10 \mu \mathrm{M})$ on the first day of treatment. Every 24 hours, cells were centrifuged for 10 minutes, the medium was removed, and subsequently fresh digoxin solution with new medium was added and cells were resuspended. This process was carried out continuously up to 168 hours ( 7 days).

Human umbilical vein endothelial cells, HMEC, and EPC were seeded into 96-well tissue culture plates at $2 \times 10^{4}$ cells and grown under standard culture conditions. Cells were treated with either a single conventional dose (MTD) or daily digoxin (metronomic therapy) for 120 hours with eight different concentrations of digoxin (0.001-50 $\mu \mathrm{M})$ adding fresh digoxin solution with new medium as previously described for retinoblastoma cell lines.

In all cases, wells with medium and PBS served as controls.

\section{Growth Inhibition Assessment}

After MTD and metronomic treatment, cell viability of Y79 and WERI-RB1 was assessed by adding 3-(4,5-dimethylthiazol-2-yl)2,5-diphenyltetrazolium bromide (MTT; Sigma-Aldrich Corp., St. Louis, MO, USA). Viable endothelial cells after MTD or metronomic treatment were counted by measuring acid phosphatase activity after incubation with the chromogenic substrate pNPP for 1 hour at $37^{\circ} \mathrm{C}$. Thereafter, the reaction was stopped with $\mathrm{NaOH}(1 \mathrm{~N})$ and the reaction product p-nitrophenol was measured at $405 \mathrm{~nm}$ using a spectrophotometer. Both techniques of cell viability assessment led to comparable IC50s in preliminary studies carried out in retinoblastoma and endothelial cells. In those studies the mean (SD) digoxin IC50 in Y79 determined using MTT and pNPP was 0.114 (0.015) and $0.116 \mu \mathrm{M}(0.010)$, respectively, and $0.016(0.005)$ and $0.013 \mu \mathrm{M}$ (0.003) for EPC $(P>0.05)$. The IC50 was defined as the concentration of the chemotherapy agent that killed $50 \%$ of the cells (or the concentration that allows a 50\% cell survival).

\section{Cell Cycle and Apoptosis Assay}

Apoptosis analysis was performed by flow cytometry using the Annexin V-FITC Apoptosis Detection Kit II (BD Pharmingen, 
San Diego, CA, USA). Briefly, $25 \times 10^{3}$ retinoblastoma and endothelial cells were seeded in 24-well plates and treated with digoxin at the IC50 in a conventional or metronomic fashion. Afterward, cells were washed and incubated for 15 minutes with FITC-annexin V in binding buffer at $37^{\circ} \mathrm{C}$. Then, cells were resuspended in propidium iodide solution and immediately analyzed by flow cytometry using FACSCalibur (BD Biosciences, San Jose, CA, USA). Cell viability and morphologic changes were also assessed by a second method under the fluorescence microscope by labeling with acridine orange (100 $\mu \mathrm{g} / \mathrm{mL}) /$ propidium iodide $(100 \mu \mathrm{g} / \mathrm{mL}$; Sigma-Aldrich Corp.) double-staining after digoxin treatment.

Cell-cycle distribution was assessed at the calculated IC50 of digoxin for each cell line after conventional and metronomic treatment using growth inhibition tests. Briefly, cells were synchronized overnight in culture medium with $1 \%$ fetal calf serum before the simultaneous expression of the cell proliferation-associated nuclear antigen $\mathrm{Ki} 67$ and DNA content (PI) was determined by flow cytometry. Cells were harvested and fixed in $70 \%$ (vol/vol) ethanol and incubated at $-20^{\circ} \mathrm{C}$ overnight. Then, cells were washed and resuspended in PBS $0.5 \%$ Nonidet P40 containing RNase A $775 \mathrm{UI} / \mathrm{mL}$, SigmaAldrich Corp.) for 30 minutes at $37^{\circ} \mathrm{C}$. Cells were immunostained using FITC-labeled anti-Ki67 (BD Transduction Laboratories, San Jose, CA, USA) for 45 minutes. Finally, cells were washed and stained with propidium iodide $(0.5 \mu \mathrm{g} / \mathrm{mL})$ and immediately analyzed by flow cytometry. Quadrant markers were set using a negative isotypic control and each phase of the cell cycle was calculated using FlowJo (Tree Star, Inc., Ashland, OR, USA) analysis software. This assay was also used to assess the degree of apoptosis under each treatment by quantifying the cells arrested in sub-G1.

\section{Pharmacokinetic Study of Digoxin After Intravitreal Dose}

A total of 17 New Zealand rabbits weighing between 1.8 and $2.2 \mathrm{~kg}$ were used for ocular and systemic pharmacokinetic characterization of digoxin after intravitreal injection of one eye. The fellow eye was used as a control. All experiments carried out in rabbits adhered to the tenets of the Institutional Committee for Animal Care of the Garrahan Hospital and the ARVO Statement for the Use of Animals in Ophthalmic and Vision Research. In all cases, the animals were fed standard laboratory food and allowed free access to water and housed under 12-hour light-dark cycles.

Sample Collection and Analytical Assay. Under general anesthesia, the animals received a single intravitreal injection of $10 \mu \mathrm{g}$ digoxin $(0.1 \mathrm{~mL})$ prepared by serial dilutions in $0.9 \%$ saline of the commercial drug product (Digoxina, Larjan, Ciudad Autonoma de Buenos Aires, Buenos Aires, Argentina) in a safety cabinet.

The selection of the dose was based on the amount of digoxin that after injection could result in pharmacologically active levels in the vitreous of a rabbit $\left(1.5 \mathrm{ml}^{27}\right)$ for at least 4 hours after injection but also, that resulted in a low systemic exposure as a surrogate of cardiac toxicity for its direct consequence in the translation to the clinics that was the ultimate goal of these studies. Thus, the dose was established by the threshold of biological activity or IC50 and we chose that obtained by Antczak et al. ${ }^{5}$ that was 10-fold higher than the value obtained in the present study. Thus, we worked with the highest dose to study if pharmacologically active levels were attained in the vitreous of the animal, the interval of time above the threshold, and if this high dose led to any measurable systemic exposure because of the concern of systemic toxicity in the clinical setting.

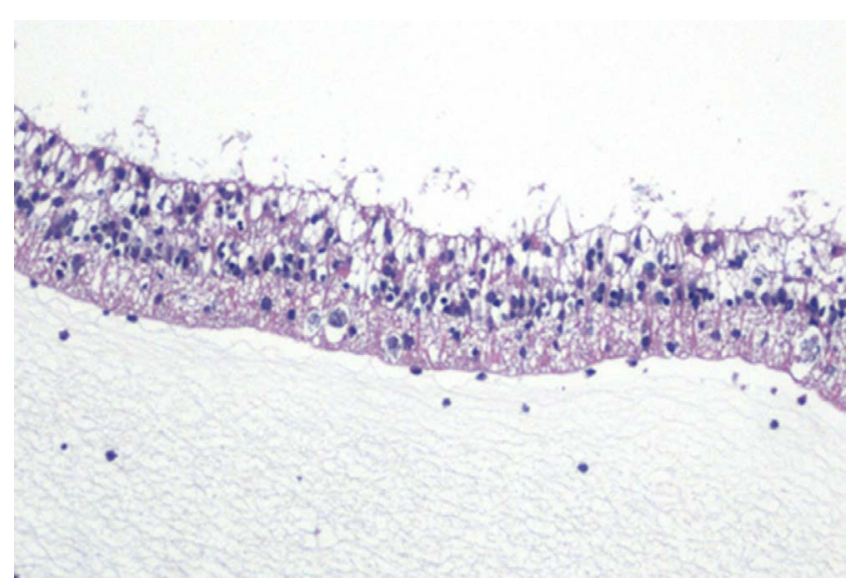

Figure 1. Representative micrograph of a retinal section after a single dose of digoxin (dose, $10 \mu \mathrm{g}$ ).

Only one vitreous sample $(100 \mu \mathrm{L})$ was obtained per eye in the anesthetized animal by aspiration from the inner region of the posterior eye chamber with an $18-\mathrm{G}$ needle at: $0.083,0.25$, $1,2,4,6,8,16,24$, and 48 hours after digoxin injection. Vitreous samples were collected and treated as previously described. ${ }^{14}$ In addition, venous blood samples $(200 \mu \mathrm{L})$ were collected from the ear vein in sodium heparinized tubes before injection and at: $0.25,0.5,1,1.5,2,3,4,6,8,16,24$, and 48 hours after intravitreal digoxin administration. ${ }^{28} \mathrm{Up}$ to two blood samples were collected from each animal except for those whose eyes were sampled at short times $(0.083$ and 0.25 hours), from whom only one blood sample was collected. The samples were immediately centrifuged and plasma was separated for digoxin assay. Finally, the animals were euthanized using an overdose of intravenous sodium pentobarbital (80 $\mathrm{mg} / \mathrm{kg}$ body weight) and both eyes were immediately enucleated. The retinal tissue was dissected from both the control and treated eyes, treated as previously reported, ${ }^{25}$ and tissue extracts were stored at $-20^{\circ} \mathrm{C}$ until assay.

Vitreous and retinal samples were quantified for digoxin by HPLC coupled with an UV detector set at $220 \mathrm{~nm}$ after validating a modified method reported by others. ${ }^{29,30}$ The linear ranges for vitreous and retina assays ranged from 0.1 to $15 \mu \mathrm{g} / \mathrm{mL}$ and 0.05 to $1.0 \mu \mathrm{g} / \mathrm{mL}$, respectively. Interday precision was less than $6.8 \%$ for both assays. Heart and kidneys from the euthanized animals were washed in cold PBS, weighed, and homogenized with methanolic acid solution in a 1-to-5 dilution using IKA T25 Ultra-Turrax (Staufen, Germany). After centrifugation, methanolic supernatants were stored at $-20^{\circ} \mathrm{C}$ until HPLC assay.

Lastly, concentration of digoxin in plasma samples was measured by microparticle enzyme immunoassay (MEIA) on the AxSYM analyzer (Abbott Laboratories, Abbott Park, IL, USA). Previously, three calibration curves were performed in plasma from normal and nontreated rabbits, supplemented with external digoxin standard solutions to assess the matrix effects when using plasma from animals.

Pharmacokinetic Analysis. A two- and a one-compartment model was fit to the vitreous and plasma digoxin concentration versus time data, respectively, for all animals using the maximum likelihood estimation method as implemented in ADAPT II (Biomedical Simulations Resource, Los Angeles, CA, USA). ${ }^{31}$ Model parameters that were estimated include the intercompartmental rate constants of transfer of digoxin from the vitreous compartment to the rest of the body (Kvc) and back to the vitreous $(\mathrm{Kcv})$, and the apparent volumes of distribution in the vitreous and the body. ${ }^{14}$ 


\section{In Vivo Safety Study After Intravitreal Digoxin}

A preliminary toxicity examination was performed in two animals in order to assess general outcome after a single intravitreal dose of digoxin corresponding to the dose used in the pharmacokinetic study. One week after a single $10-\mu \mathrm{g}$ dose to the right eye of two rabbits, retinal damage with cystic degenerative changes and complete loss of a- and b-wave amplitude and implicit time were observed compared with the parameters before injection (Fig. 1). Assuming that digoxin follows linear pharmacokinetics after intravitreal injection, we simulated the vitreous concentration data after administering a dose of $1 \mu \mathrm{g}$ based on the pharmacokinetic parameters obtained in the rabbits. The predicted vitreous concentrations were higher than the IC50 obtained in WERI-RB for approximately 7 hours. Therefore, this dose was expected to lead to pharmacologically active levels in the vitreous with potential translation into the clinics and thus, was used to evaluate the ocular toxicity after four intravitreal injections of digoxin administered every 2 weeks. Serial dilution of commercial digoxin with sterile saline was performed in order to obtain a final concentration of $10 \mu \mathrm{g} /$ $\mathrm{ml}$. Based on our previous reports in which we showed that the technique of intravitreal injection did not lead to ocular toxicity, each digoxin-treated animal was its own control using the contralateral eye treated with the diluted vehicle. ${ }^{28}$

Before intravitreal injections and electrophysiological recordings, pupillary mydriasis and corneal topical anesthesia were induced as described elsewhere. ${ }^{4,28}$ No anterior chamber paracentesis was performed. Then, the right eye was opened with an eyelid retractor and $0.1 \mathrm{~mL}$ of the digoxin solution was injected using a 33-G needle attached to a tuberculin syringe. To study the potential toxic effects of the commercial vehicle in which digoxin was dissolved, the vehicle was prepared following the composition described by the manufacturer, diluted with sterile saline, filtered through a $0.22-\mu \mathrm{m}$ filter, and $0.1 \mathrm{~mL}$ was injected in the contralateral eye in the same session. This procedure was performed every 2 weeks with a total of four administrations to each eye. After finishing the experiments the rabbits were euthanized as previously described and the eyes were immediately enucleated.

Systemic and Ocular Toxicity Evaluation. All animals were evaluated for potential signs of systemic toxicity on a weekly basis. Temporal variation of body weight, hair loss, and routine hematology tests including hematocrit, platelet count, red blood cell count, neutrophils (\% of total white blood cells), and hemoglobin level were recorded in the study period. A baseline indirect ophthalmoscopic examination was done and repeated before each digoxin or vehicle injection. Under general anesthesia (ketamine hydrochloride, $37.5 \mathrm{mg} / \mathrm{kg}$, IM and xylazine $5 \mathrm{mg} / \mathrm{kg}$, intramuscular) electrophysiological recordings (ERG) were performed in both eyes of the animals before all four intravitreal injections and 2 weeks after the last dose. Mixed rod-cone ERGs were obtained on each occasion using the technique described in our previous studies. ${ }^{4,28}$ Finally, fundus photography and fluorescein angiography (FA) were done after the fourth dose of digoxin and 1 week before enucleation.

Histopathology. Two weeks after the fourth dose of digoxin, the rabbits were euthanatized and immediately enucleated. The vitreous was separated and stored at $-20^{\circ} \mathrm{C}$ for digoxin assay. Eyes were immersed in $4 \%$ paraformaldehyde in $0.1 \mathrm{M}$ of phosphate buffer $(\mathrm{pH} 7.4)$ overnight and processed for routine histopathological examination.

\section{Statistical Analysis}

The cell survival curves for retinoblastoma and endothelial cells were presented as the percentage of surviving cells versus
Table 1. Cytotoxic Activity of Digoxin on Retinoblastoma and Endothelial Cells After Conventional and Metronomic Treatment

\begin{tabular}{lcc}
\hline Cell Line & $\begin{array}{c}\text { Conventional } \\
\text { IC50, } \boldsymbol{\mu M}\end{array}$ & $\begin{array}{c}\text { Metronomic } \\
\text { IC50, } \boldsymbol{\mu M}\end{array}$ \\
\hline Y79 & $0.100(0.027)$ & $0.101(0.040)$ \\
WERI-RB1 & $0.191(0.063)$ & $0.130(0.034)$ \\
HUVEC & $0.016(0.001)$ & $0.017(0.001)$ \\
EPC & $0.021(0.011)$ & $0.019(0.002)$ \\
HMEC & $0.019(0.002)$ & $0.013^{*}$ \\
\hline
\end{tabular}

Data are shown as means (SD).

* Only one replicate was available for HMEC with metronomic digoxin treatment.

digoxin concentration. The IC50 values were calculated by nonlinear regression analysis using GraphPad Prism (GraphPad Software, Inc., La Jolla, CA, USA). $t$-test analysis was performed to compare the IC50s obtained using conventional and metronomic treatment with digoxin on each cell line. The Mann-Whitney $U$ test was used to test for differences in ERG parameters between digoxin- and vehicle-treated eyes at different times after starting the study. We also assessed the effect of repeated intravitreal injections of digoxin on hematological parameters and body weight by means of a repeated measure ANOVA with Bonferroni test a posteriori. In all cases, the significance level was set at 0.05 .

\section{Results}

\section{Effect of Conventional and Metronomic Digoxin Treatment on Cultured Retinoblastoma Cells}

We observed strong cytotoxic activity against both retinoblastoma cell lines with calculated IC50s ranging from 0.10 to 0.19 $\mu \mathrm{M}$ (Table 1). Using a protracted treatment schedule of daily digoxin administration to retinoblastoma cells, we observed a growth inhibitory effect comparable to the cytotoxic effect obtained by a single-day treatment (Figs. 2A-D). No significant statistical difference was detected in the IC50s of both cell lines when comparing conventional with metronomic treatment $(P>0.05$, Table 1$)$.

\section{Endothelial Cell Sensitivity to Conventional and Metronomic Digoxin}

A strong and concentration-dependent antiproliferative effect was observed when HUVEC and EPC endothelial cells were exposed to conventional and single doses of digoxin (Figs. 2E, 2F, not shown for HMEC). As shown in Table 1, the mean (SD) calculated IC50s were $0.016(0.001), 0.019(0.002)$, and 0.021 (0.011) $\mu \mathrm{M}$ for HUVEC, HMEC, and EPC, respectively. When these cells were treated using a metronomic schedule with continuous exposure to digoxin over 120 hours, there was no difference in cell viability compared with the IC50s obtained under conventional treatment $(P>0.05$, Table 1 ; Figs. $2 \mathrm{G}, 2 \mathrm{H})$. In addition, HUVEC was the most sensitive endothelial cell type with an IC50 of $0.016 \mu \mathrm{M}$ after conventional treatment.

\section{Apoptosis Induced by Digoxin in Retinoblastoma and Endothelial Cells}

As shown in Figure 3A, the percentage of $\mathrm{Y} 79$ cells that underwent necrosis (Annexin-V-/PI+) after conventional treatment was higher than that obtained after metronomic treatment. However, no differences in the percentage of necrotic cells were observed between treatment schemes in 

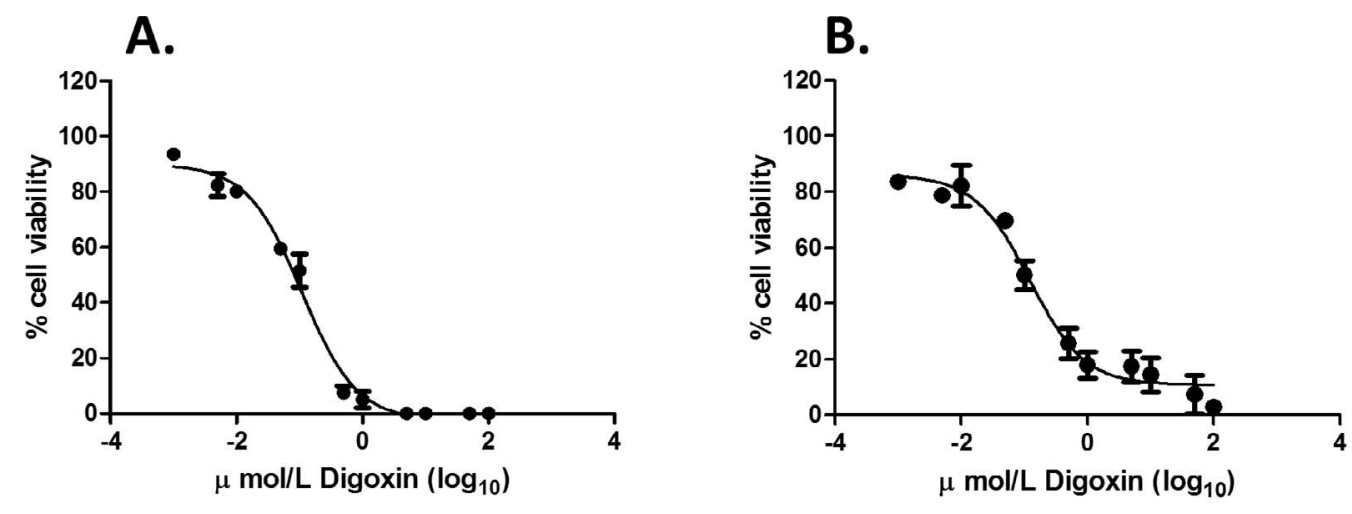

\section{C.}

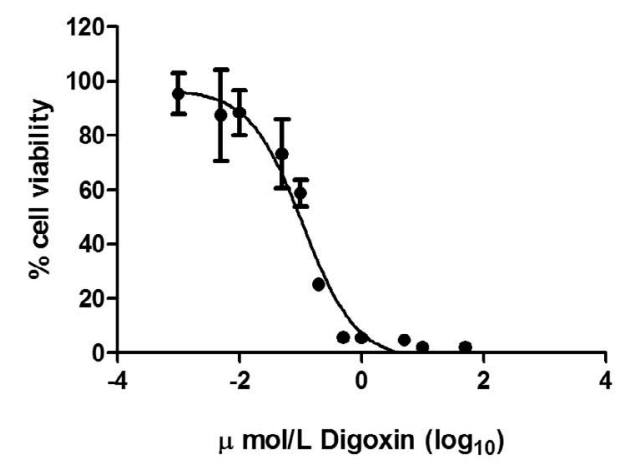

E.

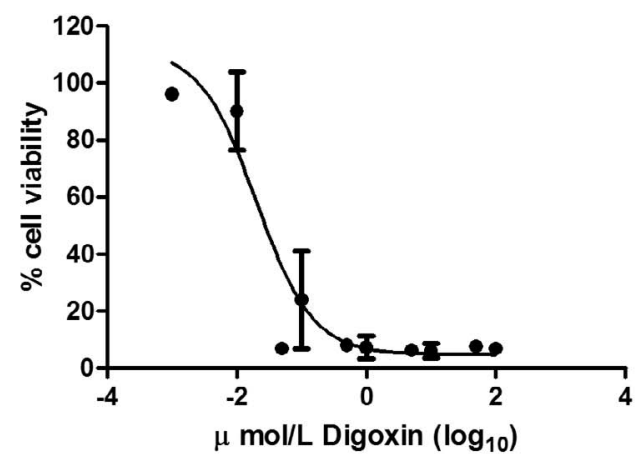

G.

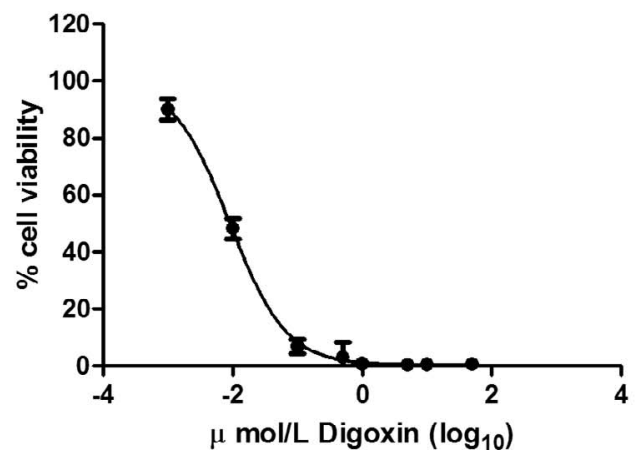

D.

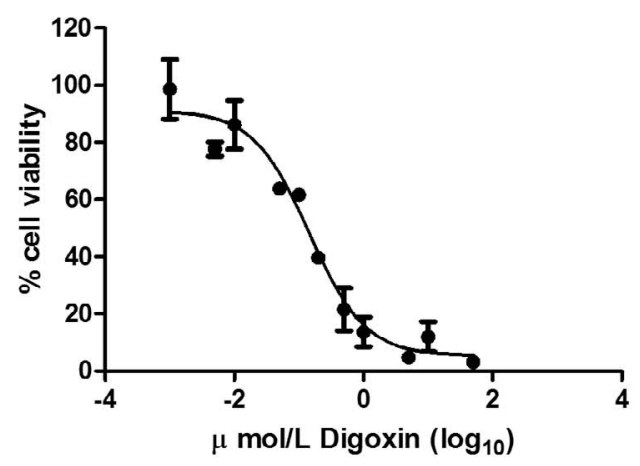

F.

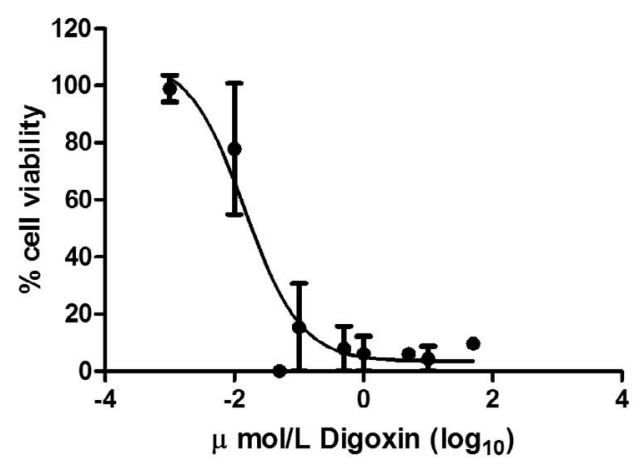

H.

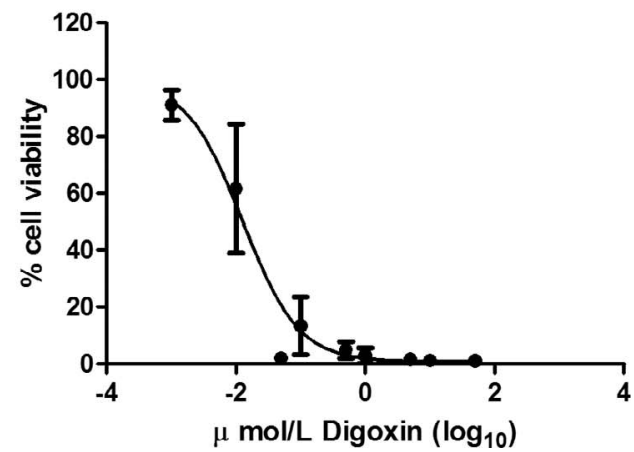

Figure 2. Effect of digoxin on retinoblastoma and endothelial cell proliferation in a conventional and a metronomic treatment scheme. (A, B) Growth inhibition assay performed on Y79 and WERI-RB1 cell lines, respectively, using MTT after 72-hour incubation of a conventional regimen and (C, D) metronomic treatment for 7 days with different digoxin concentrations; (E, F) growth inhibition assessment of HUVEC and EPC cell lines, respectively after conventional and $(\mathbf{G}, \mathbf{H})$ metronomic digoxin treatment. Symbols represent percentage of cell proliferation as compared with untreated control cells, expressed as means (SEM) of three independent experiments, each performed in triplicates. 
A

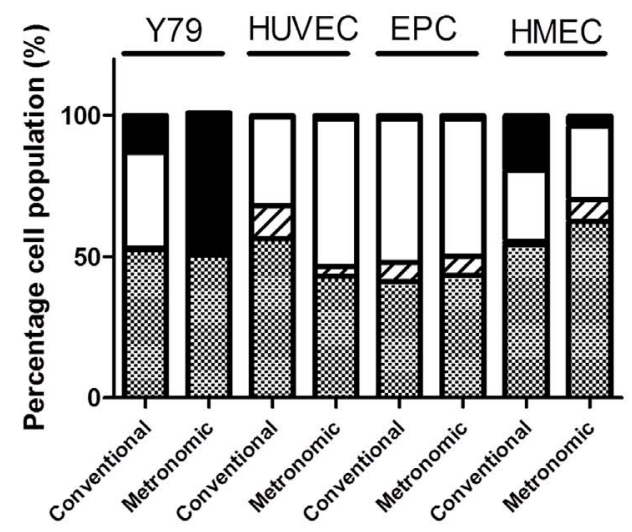

B

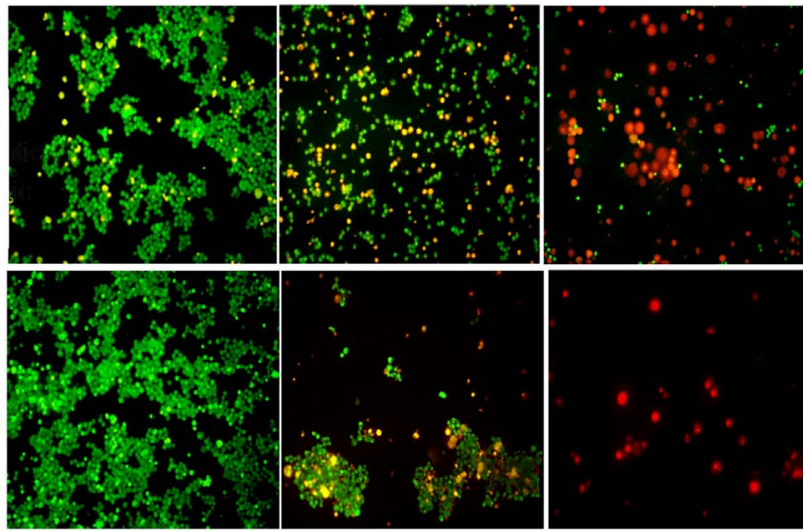

C

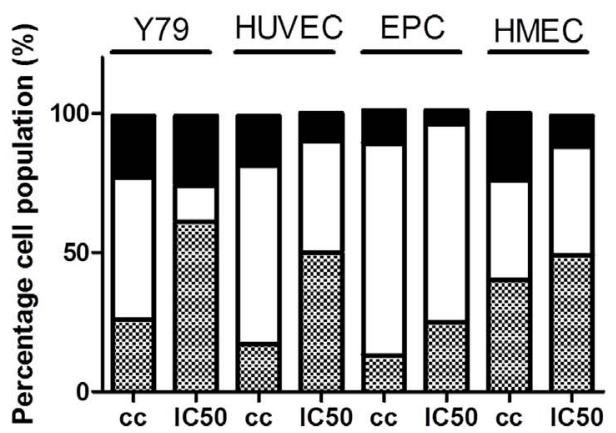

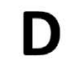

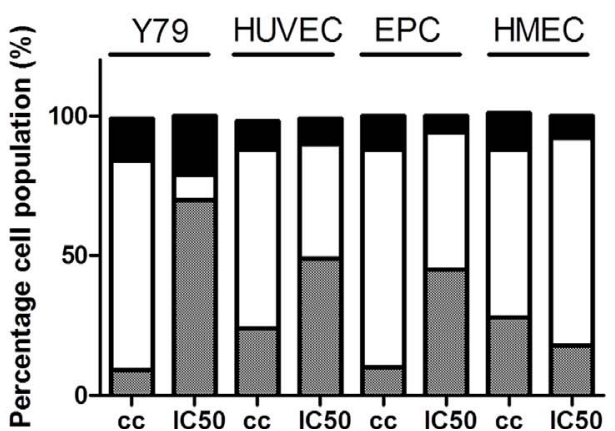

Figure 3. Effect of digoxin on the apoptosis and cell cycle of retinoblastoma and endothelial cells after conventional and metronomic treatment. (A) Apoptosis was examined using annexin V-FITC/PI staining. Percentages of viable (dotted bars), early apoptotic (right dashed bars), and late apoptotic (white bars)/necrotic cells (black bars) are shown after conventional ( 72 hours) and metronomic ( 7 days) digoxin treatment. (B) Morphologic changes of Y79 cells treated with digoxin after one dose at the IC50 (upper row, conventional) or continuous treatment (lower row, metronomic) observed by fluorescent microscope (magnification: $\times 200$ ). Untreated Y79 cells demonstrated a normal structure without prominent apoptosis after conventional or metronomic treatment (stained green with acridine orange). Y79 cells after conventional or metronomic exposure to the IC50 of digoxin (middle picture), with clear hallmarks of late apoptosis are shown in orange using propidium iodide. (C) Effect of conventional and (D) metronomic digoxin exposure on cell cycle distribution of retinoblastoma and endothelial cells. Dotted bars, percentage of cells in G0; white bars, percentage of cells in G1; black bars, percentage of cells in G2/M. Digoxin induced a cell cycle arrest at G0 phase after treatment at the IC50 despite the treatment fashion and cell line.

endothelial cells. After both treatment schemes at digoxin IC50 the percentage range of apoptosis was $37 \%$ to $58 \%$.

These results were confirmed using acridine orange/ propidium as a second technique. Using both conventional and metronomic schemes, cells exhibited chromatin condensation, shown as bright green fluorescence, and a reduction of cell size and nuclear fragmentation (Fig. 3B). Late-stage apoptosis induced by digoxin was identified by the reddishorange color obtained by propidium iodide binding to denatured DNA. The same morphologic changes were observed in the three endothelial cell types (data not shown).

Altogether, our results demonstrate that the proportion of apoptotic cells remained constant between treatment schemes in all cell lines except in retinoblastoma cells, which mostly suffered necrotic events.

\section{Digoxin Induces G0 Cell Cycle Arrest}

To examine the effects of digoxin on the cell cycle, we studied cell cycle progression in the Y79 retinoblastoma cell line and endothelial HUVEC, HMEC, and EPC cell types by flow cytometry using ki-67 and PI double-staining. We observed that at concentrations of digoxin effective to reduce the retinoblastoma and endothelial cell number by $50 \%$ upon either conventional (Fig. 3C) or metronomic (Fig. 3D) treatment, impaired cell-cycle progression induced cells to accumulate in G0. The increase in the G0-phase cell population was accompanied by a concomitant reduction of cells in the G1 phase. This arrest in G0 was more evident in the retinoblastoma Y 79 cell line with an increase from $26 \%$ of the control-cell fraction to $61 \%$ in the digoxin treated-cell fraction after conventional treatment. The increase in G0 was accompanied by a subsequent decrease of the cell fraction in G1 from $51 \%$ (control cells) to 13\% (digoxin-treated cells) with similar fractions at G2/M. Results after the metronomic scheme at the IC50 were even more evident in Y79 cells, showing an increase at G0 from 9\% of the control-cell fraction to $70 \%$ of the digoxin-treated cell fraction. Again, the observed increase at G0 was related to a subsequent decrease of the cell fraction in G1 from $75 \%$ (control cells) to $9 \%$ (digoxin-treated cells). 
A.

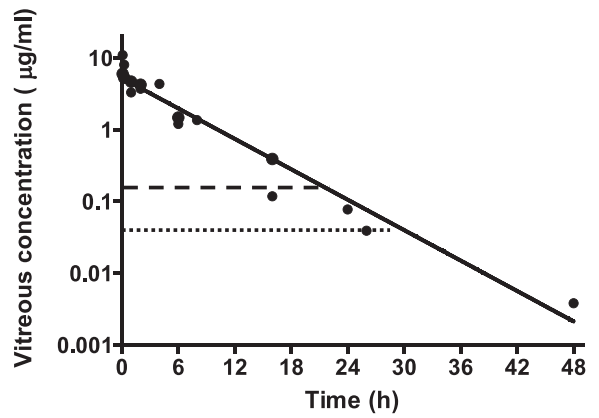

B.

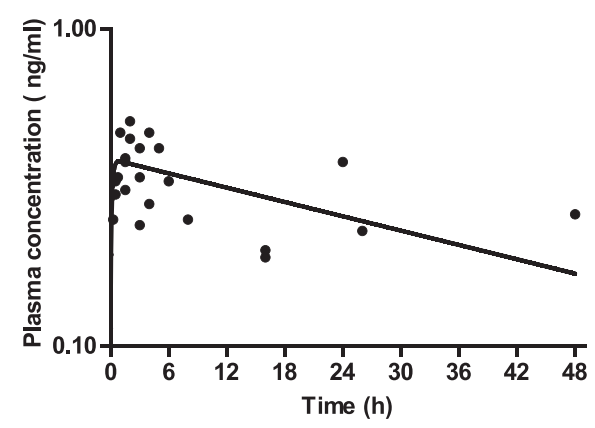

C.

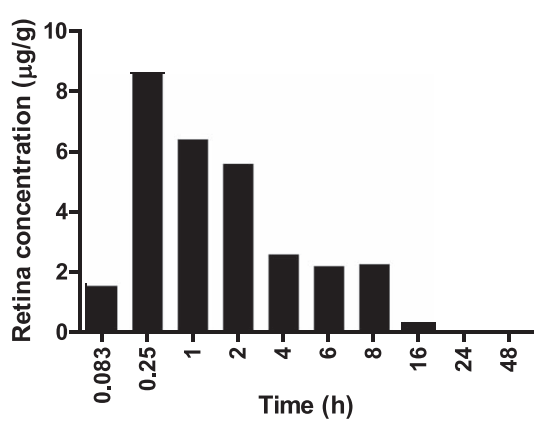

FIGURE 4. Ocular digoxin pharmacokinetics after a single intravitreal injection. Digoxin concentration versus time profile in (A) vitreous, (B) plasma, and $(\mathbf{C})$ retina of treated eyes after a single intravitreal injection of $10 \mu \mathrm{g}$ digoxin. Full symbols represent individual data points for vitreous and plasma concentrations, the solid lines show the predicted concentrations. The dotted and dashed lines (A) represent digoxin IC50 obtained in Y79 and WERI-RB1, respectively.

Furthermore, a similar effect was seen in HUVEC in which a cell arrest in G0 increased from $17 \%$ to $50 \%$ after conventional treatment at the expense of a reduction in G1 from $64 \%$ to $40 \%$. Similar changes in the percentage of cells at the different phases of the cell cycle were observed after the metronomic treatment of HUVEC. Finally, conventional and metronomic treatment of EPC and HMEC with digoxin led to similar but more modest cell-cycle arrests as previously described for HUVECs and Y79 cells. The number of cells in the G2/M phases of the cell cycle showed no changes when comparing digoxin-treated cells with the controls of the different cell lines.

\section{Digoxin Pharmacokinetics After Intravitreal Injection}

The disposition of digoxin after a single dose of $10 \mu \mathrm{g}$ into the vitreous humor of rabbits was well described by a twocompartment model as shown in Figure 4A. A total of 17 vitreous samples were obtained at different time points. Three animals were reported to the Local Committee and were not included in the present study due to an infection in the eye that required treatment with antibiotics, hematologic disorder confirmed in the routine testing, and the third animal died during anesthesia. The maximum vitreous concentration $\left(C_{\text {max }}\right)$ was $8.5 \mu \mathrm{g} / \mathrm{mL}$ attained 5 minutes after the intravitreal injection. Digoxin was not detected in the retina or vitreous of the contralateral eye at any time post injection.

Our results showed that after a single intravitreal dose of 10 $\mu \mathrm{g}$, plasma levels $(n=25)$ were below $0.5 \mathrm{ng} / \mathrm{mL}$ at all times after the injection except for one animal that showed a concentration of $0.7 \mathrm{ng} / \mathrm{mL} 30$ minutes after intravitreal injection (Fig. 4B). Interestingly, the digoxin area under the plasma concentration versus time calculated up to 48 hours after the administration $\left(A U C_{p l}\right)$ was $12.6 \mathrm{ng} \times \mathrm{h} / \mathrm{mL}$, corresponding to $0.04 \%$ of the AUC reached in the vitreous compartment $\left(A U C_{v i t}, 33.2 \mu \mathrm{g} \times \mathrm{h} / \mathrm{mL}\right)$.

Retinal digoxin concentrations $(n=17)$ versus time are depicted in Figure 4C. The maximum retinal concentration predicted by the model was $8.5 \mu \mathrm{g} / \mathrm{g}$ of tissue attained 15 minutes after administration. In addition, retinal concentrations were quantifiable up to 16 hours. Pharmacokinetic parameters after a single intravitreal injection of digoxin are reported in Table 2 .

Finally, kidney and heart samples from the animals were nonquantifiable for digoxin at all times after intravitreal injection.

\section{Ocular and Systemic Toxicity After Multiple Intravitreal Digoxin}

Animals treated with four doses of intravitreal digoxin showed no significant changes in body weight and hematocrit, platelet, red blood cell, or neutrophil counts (compared with percent of total white blood cells), or hemoglobin content during the study period $(P>0.05)$.

Serum digoxin was nondetectable 2 weeks after each intravitreal injection (prior to the next dose).

Eyes treated with digoxin or the diluted vehicle did not show any evidence of inflammation during the follow-up period. The cornea, anterior chamber, and vitreous remained clear in all but two eyes. In these eyes cataracts developed after the second and third injection with diluted vehicle, respectively. No fundus changes attributable to drug toxicity were evident in vehicle-treated eyes but two eyes of the digoxintreated group showed a hypopigmented focal area in the inferior retina corresponding to retinal atrophy and choroidal hypovascularity. Lastly, Figures $5 \mathrm{~A}$ and $5 \mathrm{~B}$ depict the digoxintreated eye of a representative animal 2 weeks after the fourth injection. Fundoscopy and FA showed no decrease in the number or changes in the quality of retinal vessels.

\section{Electrophysiological Studies}

We found no significant changes in a-wave and b-wave implicit times when comparing digoxin- to vehicle-treated eyes or digoxin-treated eyes before any injection and at different times during the study period $(P>0.05)$. However, a significant reduction in b-wave and a-wave amplitude was observed in the digoxin-treated eyes at least 2 weeks after the second intravitreal injection compared with the parameter obtained in the same eye before starting treatment as shown in Table 3

Table 2. Pharmacokinetic Parameters of Digoxin After a Single-Dose Intravitreal Injection in Rabbits

\begin{tabular}{|c|c|c|c|}
\hline $\begin{array}{c}\text { Pharmaco- } \\
\text { kinetic } \\
\text { Parameter }\end{array}$ & $\begin{array}{l}\text { Vitreous Humor } \\
\text { (Injected Eye) }\end{array}$ & Plasma & $\begin{array}{c}\text { Retina* }^{*} \\
\text { (Injected Eye) }\end{array}$ \\
\hline$C_{\text {max }} \dagger$ & $8.5 \mu \mathrm{g} / \mathrm{ml}$ & $0.0004 \mu \mathrm{g} / \mathrm{ml}$ & $8.5 \mu \mathrm{g} / \mathrm{g}$ \\
\hline AUC & $33.2 \mu \mathrm{g} \times \mathrm{h} / \mathrm{ml}$ & $0.0126 \mu \mathrm{g} \times \mathrm{h} / \mathrm{ml}$ & $42.4 \mu \mathrm{g} \times \mathrm{h} / \mathrm{g}$ \\
\hline
\end{tabular}


A

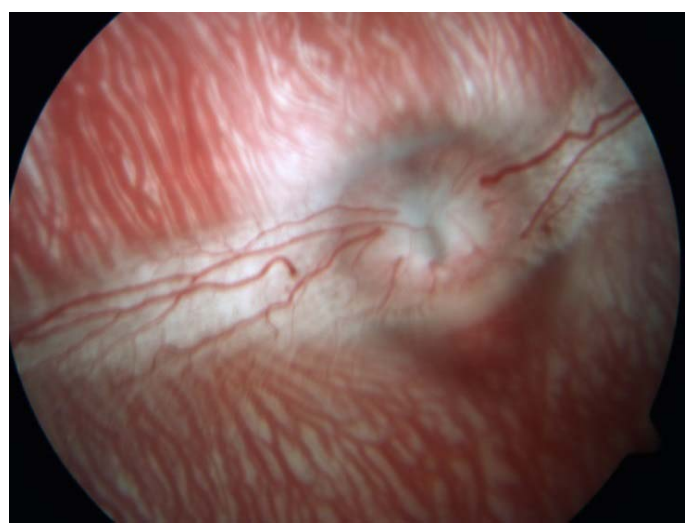

B

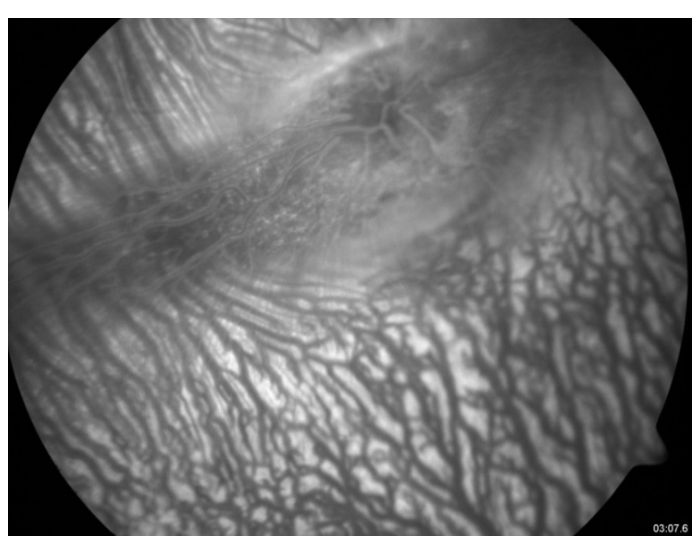

C

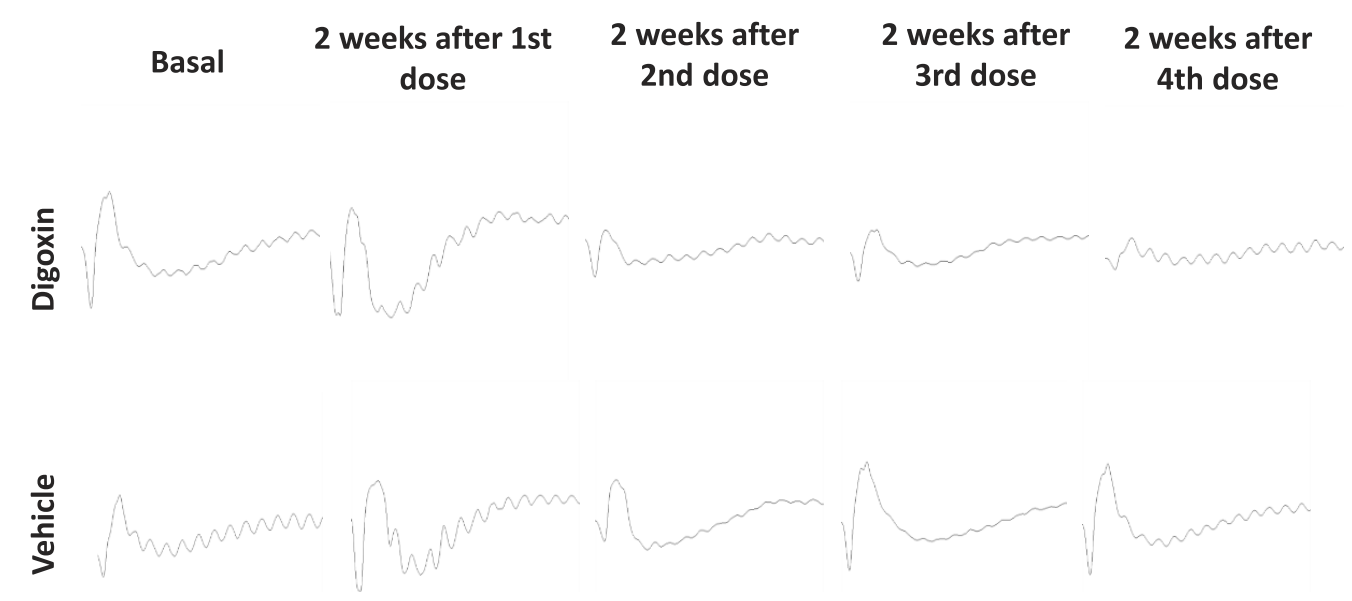

Figure 5. (A) Representative color fundus and (B) fluorescein angiography of a digoxin-treated eye showing normal vessels. (C) Representative electroretinogram response with time after multiple intravitreal injections of digoxin in a rabbit eye (top, digoxin-treated eye with four biweekly injections of $1 \mu$ digoxin; bottom, vehicle-treated eye).

$(P<0.05)$. Two weeks after the third dose of digoxin, the aand b-wave amplitude declined significantly in the digoxincompared with the vehicle-treated eyes as depicted for a representative animal in Figure 5C $(P<0.05)$. No recovery in a- or b-wave amplitude could be recorded after 2 weeks of the full treatment schedule (four doses injected every 2 weeks) and before enucleation $(P<0.05)$. No statistical difference was found in a-wave or b-wave amplitude in vehicle-treated eyes throughout the entire follow-up period.

Thus, the present data shown in Table 3 confirm that biweekly intravitreal digoxin injections of $1 \mu \mathrm{g}$ induced retinal toxicity according to the ERG responses after the third injection.

\section{Histologic Analysis}

Light microscopy of retinal sections of vehicle- and digoxintreated eyes revealed that the diluted vehicle induced no toxic effects in the peripheral, equatorial, and posterior retina (Figs. 6A, 6C, 6E). However, we found histologic evidence of focal outer retinal atrophy in digoxin-treated eyes. The outer nuclear layers of the retina and the photoreceptor structures were severely impaired but the damage was constricted to the equatorial area (Fig. 6D). Those areas where the integrity of the outer retina was lost were in continuity with intact retina from the peripheral (Fig. 6B) and posterior retina (Fig. 6F). Medullated nerve fibers showed normal appearance in both vehicle and digoxin-treated eyes (Figs. 6G, 6H, respectively). Lastly, the optic discs of vehicle and digoxin-treated eyes showed no evidence of vascular alterations and myelin sheaths remained unaltered as well as those eyes from treated with the vehicle (Figs. 6H, 6J, respectively).

\section{Discussion}

We confirm previous results from high-throughput screening analysis showing that digoxin exerts a potent cytotoxic effect on retinoblastoma cell lines with an IC50 between 0.10 and $0.19 \mu \mathrm{M}$. The potential discrepancies between the present results and the original high-throughput screening study that showed higher IC50s for digoxin in WERI-RB1 and Y79 cell lines may be attributable to different incubation times for drug exposure to the cells and the density of cells per well used for the cytotoxicity studies. ${ }^{5,32}$

Current treatment of eyes with vitreous seeds includes multiple intravitreal injections of melphalan. ${ }^{33}$ This treatment has led to the ocular survival of eyes that could not be saved in 
TABLE 3. Electroretinography Response After Intravitreal Digoxin

\begin{tabular}{|c|c|c|}
\hline & \multicolumn{2}{|c|}{ Eye Treatment Group } \\
\hline & $\begin{array}{l}\text { Digoxin- } \\
\text { Treated }\end{array}$ & $\begin{array}{l}\text { Vehicle- } \\
\text { Treated }\end{array}$ \\
\hline & \multicolumn{2}{|c|}{ b-wave } \\
\hline \multicolumn{3}{|l|}{ Amplitude } \\
\hline Baseline & $159.5(7.4)$ & $139.5(9.1)$ \\
\hline After first dose & $118.9(22.0)$ & $152.1(3.7)$ \\
\hline After second dose & $66.3(10.4)^{*}$ & $120.6(53.4)$ \\
\hline After third dose & $56.3(13.8)^{*} \dagger$ & $173.7(12.9)$ \\
\hline After fourth dose & $28.8(12.5)^{*} \dagger$ & $175.2(26.8)$ \\
\hline \multicolumn{3}{|l|}{ Implicit time } \\
\hline Baseline & $33.9(1.7)$ & $33.8(1.4)$ \\
\hline After first dose & $32.4(1.4)$ & $33.2(1.6)$ \\
\hline After second dose & $32.5(2.9)$ & $30.1(1.7)$ \\
\hline After third dose & $33.7(2.0)$ & $33.2(2.2)$ \\
\hline After fourth dose & $25.6(8.6)$ & $34.0(0.8)$ \\
\hline & \multicolumn{2}{|c|}{ a-wave } \\
\hline \multicolumn{3}{|l|}{ Amplitude } \\
\hline Baseline & $88.4(4.3)$ & $61.6(10.1)$ \\
\hline After first dose & $79.8(13.4)$ & $88.5(10.4)$ \\
\hline After second dose & $59.4(9.0)$ & $54.8(15.1)$ \\
\hline After third dose & $47.6(6.3)^{*} \dagger$ & $73.3(6.2)$ \\
\hline After fourth dose & $14.4(5.2)^{*} \dagger$ & $69.9(1.9)$ \\
\hline \multicolumn{3}{|l|}{ Implicit time } \\
\hline Baseline & $12.9(0.4)$ & $11.8(0.7)$ \\
\hline After first dose & $13.9(0.4)$ & $13.1(0.5)$ \\
\hline After second dose & $13.3(0.1)$ & $12.7(0.5)$ \\
\hline After third dose & $13.0(0.6)$ & $11.9(0.3)$ \\
\hline After fourth dose & $11.0(3.8)$ & $12.1(0.3)$ \\
\hline
\end{tabular}

Electroretinographic amplitude and implicit time recordings in rabbits after four biweekly injections of $1 \mu \mathrm{g}$ digoxin or diluted vehicle. Data is shown as mean (SD).

${ }^{*} P<0.05$ with respect to baseline (before digoxin injections).

$\dagger$ To the left eyes at the same time post treatment.

the past with other routes for drug delivery using classical antineoplastic agents. On the other hand, we previously reported the toxicity to the retina and the decline in vision with time of treatment/number of injections of melphalan. ${ }^{4}$ Moreover, despite the attained improvement, we still face with eyes that relapse to intravitreal melphalan. ${ }^{33}$ Specifically, for these eyes, nowadays there are no alternative agents active against retinoblastoma and most patients undergo enucleation. Therefore, digoxin may be an options based on its potent cytotoxic activity against retinoblastoma cell lines.

Consistent with previous reports we found that, at concentrations effective in reducing the retinoblastoma cells by $50 \%$, digoxin exhibited proapoptotic activity. ${ }^{5,8}$ Complex pathways have previously been reported to trigger apoptosis after cardenolide treatment of different cell lines including changes in intracellular ion homeostasis due to the inhibition of $\mathrm{Na}+\mathrm{K}+$ ATPase.$^{6,8}$ However, further studies are necessary to assess the mechanism of digoxin-induced growth arrest in retinoblastoma cells.

Digoxin may also exert its antitumor effect in retinoblastoma by targeting the endothelium leading to antiangiogenic effects. The role of tumor angiogenesis in retinoblastoma growth is well documented. ${ }^{34,35}$ Therefore, we chose three types of endothelial cells, HUVEC, EPC, and HMEC, to evaluate digoxin-induced antiangiogenesis. Human umbilical vein endothelial cells are popular cells because of their relative ease of isolation and because they represent the macrovascular component while HMEC represent the microvascular component of a tumor. ${ }^{36}$ Endothelial progenitor cells are found in the bone marrow or within the pre-existing vasculature and they represent more immature endothelial cells than HUVEC and HMEC, participating in neovascularization including vasculogenesis and angiogenesis. ${ }^{37}$ These three cell types are models of endothelial tumor cells and were used to distinguish them from normal retinal or choroidal vasculature. Thus, we could support a possible pharmacological effect as opposed to the toxicity profile against the normal ocular tissue. In addition, Mesri et al. ${ }^{38}$ described that the molecular phenotype of the endothelium of vessels in tumors differed from endothelial cells isolated from matched adjacent normal human tissue. Specifically, they showed an upregulation of ATP1B3, the beta subunit of the $\mathrm{Na}+/ \mathrm{K}+$ ATPase. Taking into account that this ATPase enzyme is the site of action of digoxin, further studies are needed to assess the effect of its overexpression in tumor endothelial cells and its relevance in the pharmacological effect of digoxin. Based on the IC 50 obtained after 72 hours of digoxin exposure, the most sensitive cell type was the HUVEC. Although small differences were encountered among the three types, all showed an IC50 of approximately $20 \mathrm{nM}$. In addition, we showed that apoptosis was the mechanism of digoxininduced death in endothelial cells. Previous reports by others showed an IC50 of approximately $210 \mathrm{nM}$ after treating HUVEC cells with digoxin at a range of concentrations for different times. ${ }^{15,39}$ In those studies the IC50 was calculated after exposing the cells to digoxin for 48 hours, however, we exposed cells to digoxin for 72 hours under the conventional schedule. In addition, those reports showed that the cytotoxic effect was concentration- and time-dependent. Thus, the differences in the HUVEC IC50s between previous reports and ours may be mainly due to the time-effect of digoxin on cell growth. ${ }^{32}$ Altogether, this is the first study demonstrating the effect of digoxin on EPC and HMEC endothelial cell types. Finally, the results obtained from in vitro studies may differ from in vivo results due to the interactions with vascular mural cells, neurons, and glial cells needed for normal retinal endothelial cell function. Thus, further studies are necessary to confirm our results in vivo.

After a single intravitreal 10- $\mu$ g dose of digoxin administered to rabbits, we observed a favorable disposition of the drug with high and sustained vitreous exposure and low plasma concentrations. Considering the vitreous volume of the rabbit, a maximum vitreous concentration $\left(C_{\max , \text { vit }}\right)$ between 6.7 and $8.3 \mu \mathrm{g} / \mathrm{mL}$ was expected to be attained shortly after intravitreal delivery. ${ }^{27}$ In agreement with this, our model predicted a $C_{\text {max }}$, vit of $8.5 \mu \mathrm{g} / \mathrm{mL} 5$ minutes after injection. Based on the IC50 obtained in the present study, an active pharmacological concentration may be expected for 24 hours after intravitreous administration (Fig. 4A). Interestingly, plasma digoxin levels were below the lower limit of the therapeutic window ${ }^{13}$ at all times after injection of a single dose. The large volume of distribution of digoxin is due to the high affinity for skeletal and cardiac muscles and the kidney. However, we observed no measurable concentrations of digoxin in the kidneys or hearts of our animal model. We observed a striking plasma-to-vitreous exposure ratio that showed systemic digoxin exposure to be only $0.04 \%$ of the amount in the vitreous compartment. Therefore, after a 10- $\mu$ g dose we observed a low plasma bioavailability of digoxin and thus, this dose was not expected to lead to systemic or cardiovascular toxicity. However, this single dose was toxic to the retina of the rabbits, and thus could not be translated to a potential human use unless a modification to the scheme of treatment was introduced.

After four biweekly intravitreal injections in rabbits, we registered no vascular retinal changes or systemic toxicity. Nevertheless, we did observe local injury only at defined areas 
A

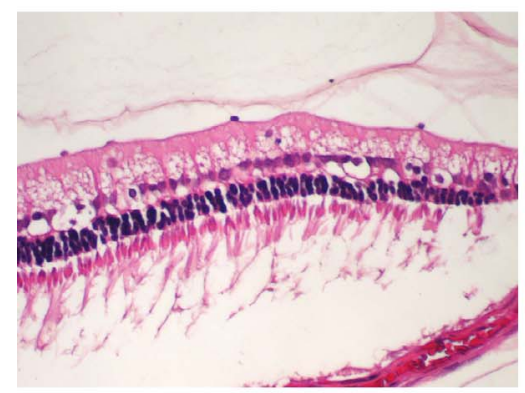

C

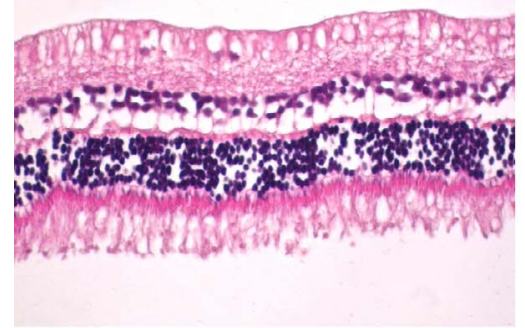

E

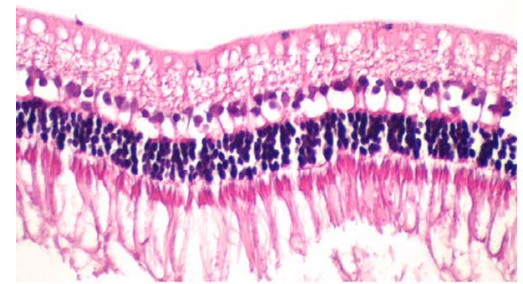

G
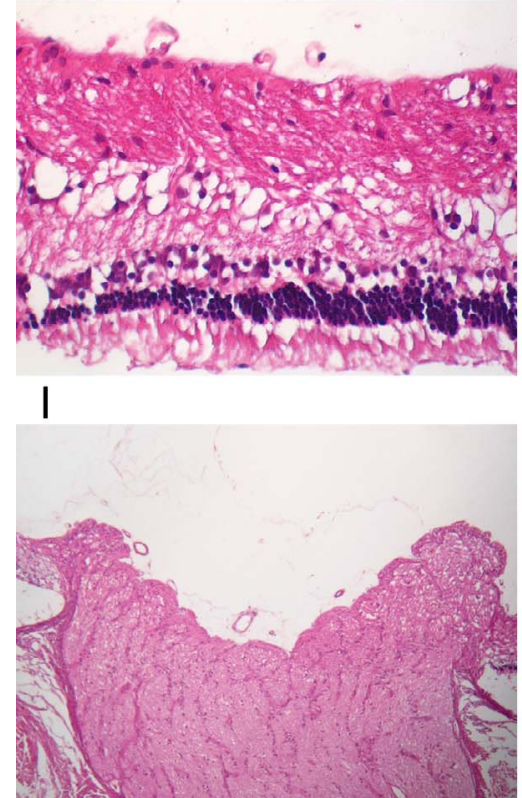

B

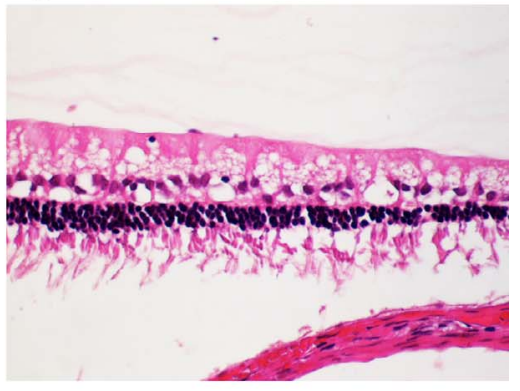

D

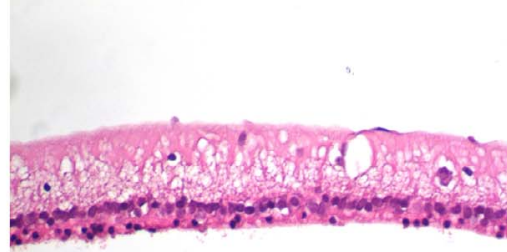

F

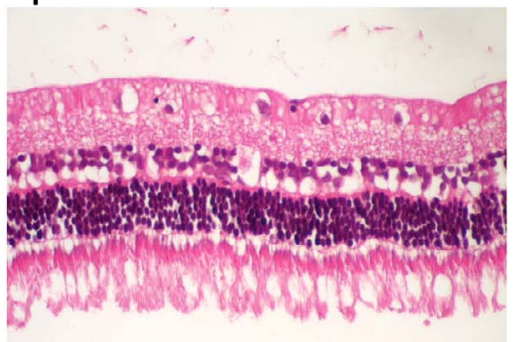

H

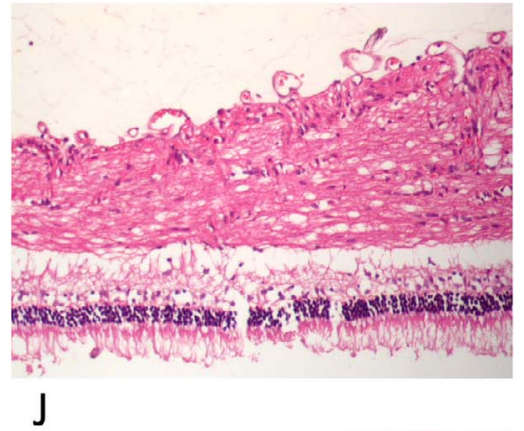

J

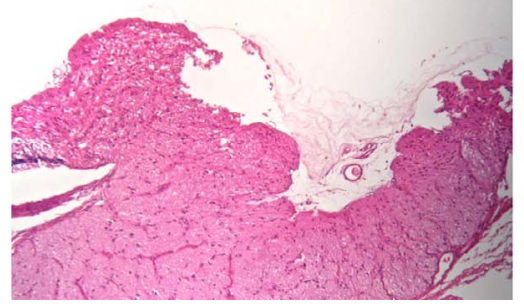

FigURE 6. Representative micrographs of the retinal sections and optic disks 2 weeks after the fourth dose of intravitreal digoxin (hematoxylin and eosin stain, $[\mathbf{A}-\mathbf{H}]$ original magnifications $\times 125$, and $[\mathbf{I}, \mathbf{J}] \times 25)$. Left column: vehicle-injected eye (control) and right column: digoxin-injected eye of the same rabbit. The vehicle-treated eye showed a normal appearance of the peripheral (A), equatorial (C), and posterior (E) retina and medullated nerve fibers (G). The digoxin-treated eye of the same rabbit showed marked atrophy of the outer retinal layer in the equatorial area (D) while the peripheral $(\mathbf{B})$, posterior $(\mathbf{F})$, and medullated nerve fibers $(\mathbf{H})$ were not affected. The optic disc and surface blood vessels (I, $\mathbf{J})$ were normal in the control and digoxin-injected eyes. 
that involved the outer retina (Fig. 6D) in the digoxin-treated but not in the vehicle-injected eyes. Hence, the retinal damage was not associated with vascular toxicity and necrosis. Furthermore, the ERGs of the digoxin-treated eyes showed a significant decrease in the a-wave and b-wave amplitude before the third dose compared with the pretreatment state $(P<$ $0.05)$. This reduction in both amplitudes may be the result of the injected volume or a toxic effect of the injected vehicle; however, the ERGs remained unchanged in vehicle-treated eyes during the study period and the $\mathrm{a}$ - and b-wave amplitude declined significantly in the digoxin-treated eyes compared with the vehicle-treated eyes $(P<0.05)$ after three doses with no recovery. Interestingly, we found no significant changes in aand b-wave implicit times in digoxin-treated eyes at a 1- $\mu \mathrm{g}$ dose. The vehicle-treated eyes showed normal ERGs and histopathology confirming that the elevation of IOP from increased intraocular volume after injection was not the cause of this finding. Altogether, these results suggest that the observed toxicity implicates digoxin as the toxic agent.

One way to circumvent high exposures for short periods of time but still attaining the same drug exposure is to increase the frequency of drug administration but using lower doses or a sustained-release formulation. This approach may yield the same exposure-related pharmacological activity, associated with lower toxicity, as it avoids tissue exposure to high local drug concentrations that may be cytotoxic to both normal and tumor cells. Conversely, conventional chemotherapy (using the maximum-tolerated dose) targets rapidly dividing tumor cells, but also cells from normal tissues, triggering a series of adverse and sometimes life-threatening events. Therefore, in this study we examined the value of metronomic treatment with digoxin in endothelial and retinoblastoma cell types. We observed no difference in the calculated IC50 of the three endothelial cell types comparing the conventional with the continuous treatment $(P>0.05)$. Similarly, we did not observe a decrease in the IC50 of retinoblastoma cell lines when comparing both treatment schedules. Altogether, continuous exposure to digoxin may not be a better treatment option as it does not allow a dose reduction compared with conventional treatment for retinoblastoma control and antiangiogenic effect.

In conclusion, the present study showed that digoxin exerts a strong antiangiogenic effect and cytotoxicity against retinoblastoma in vitro and that the antiproliferative effects of digoxin were mediated mostly by apoptosis inducing cell-cycle arrest at G0. Digoxin showed favorable vitreous pharmacokinetics attaining pharmacologically active concentrations for up to 24 hours after a single intravitreal injection in the rabbit eye while plasma concentrations were far below the concentration that triggers cardiac toxicity in humans. Therefore, based on our results, intravitreal digoxin may be considered for further clinical study in retinoblastoma patients with relapsed vitreous seeds.

\section{Acknowledgments}

The authors thank Gustavo Williams for general assistance with the animal care and experiments, Alejandra Rodiño for technical assistance with the analytical assay of digoxin in plasma, and Andrea Bosaleh for her assistance in the histologic assessment of the rabbits in the pilot study.

Supported by a 2013 ARVO/Merck Collaborative Research Fellowship (Rockville, MD, USA), Fund for Ophthalmic Knowledge (GLC, ACF; NY, NY, USA), Instituto Nacional del Cáncer, (Buenos Aires, Argentina), and Fundación Natalie D Flexer de Ayuda al Niño con Cáncer (GLC, ACF; Buenos Aires, Argentina).

Disclosure: U. Winter, None; E. Buitrago, None; H.A. Mena, None; M.J. Del Sole, None; V. Laurent, None; S. Negrotto, None; J. Francis, None; E. Arana, None; M. Sgroi, None; J.O.
Croxatto, None; H. Djaballah, None; G.L. Chantada, None; D. Abramson, None; P. Schaiquevich, None

\section{References}

1. Gobin YP, Dunkel IJ, Marr BP, Brodie SE, Abramson DH. Intraarterial chemotherapy for the management of retinoblastoma: four-year experience. Arch Ophthalmol. 2011;129:732-737.

2. Abramson DH. Retinoblastoma: saving life with vision. Annu Rev Med. 2014;65:171-184.

3. Munier FL, Gaillard MC, Balmer A, et al. Intravitreal chemotherapy for vitreous disease in retinoblastoma revisited: from prohibition to conditional indications. $\mathrm{BrJ}$ Ophthalmol. 2012;96:1078-1083.

4. Francis JH, Schaiquevich P, Buitrago E, et al. Local and systemic toxicity of intravitreal melphalan for vitreous seeding in retinoblastoma: a preclinical and clinical study. Ophthalmology. 2014;121:1810-1817.

5. Antczak C, Kloepping C, Radu C, et al. Revisiting old drugs as novel agents for retinoblastoma: in vitro and in vivo antitumor activity of cardenolides. Invest Ophthalmol Vis Sci. 2009;50: 3065-3073.

6. Slingerland M, Cerella C, Guchelaar HJ, Diederich, M, Gelderblom, H. Cardiac glycosides in cancer therapy: from preclinical investigations towards clinical trials. Invest New Drugs. 2013;31:1087-1094.

7. Menger L, Vacchelli E, Adjemian S, et al. Cardiac glycosides exert anticancer effects by inducing immunogenic cell death. Sci Transl Med. 2012;4:143ra99.

8. López-Lázaro, M. Digitoxin as an anticancer agent with selectivity for cancer cells: possible mechanisms involved. Expert Opin Ther Targets. 2007;11:1043-1053.

9. Prassas I, Karagiannis GS, Batruch I, Dimitromanolakis A, Datti A, Diamandis EP. Digitoxin-induced cytotoxicity in cancer cells is mediated through distinct kinase and interferon signaling networks. Mol Cancer Ther. 2011;10:2083-2093.

10. López-Lázaro M, Pastor N, Azrak SS, Ayuso MJ, Austin CA, Cortes F. Digitoxin inhibits the growth of cancer cell lines at concentrations commonly found in cardiac patients. $J$ Nat Prod. 2005;68:1642-1645.

11. Patel M, Paulus YM, Gobin YP, et al. Intra-arterial and oral digoxin therapy for retinoblastoma. Ophthalmic Genet. 2011; 32:147-150.

12. Schaiquevich $\mathrm{P}$, Buitrago E, Ceciliano A, et al. Pharmacokinetic analysis of topotecan after superselective ophthalmic artery infusión and periocular administration in a porcine model. Retina. 2012;32:387-395.

13. Shargel Leon, Yu Andrew. Application of pharmacokinetics to clinical situations. In: Witz M, Naglieri C, ed. Applied Biopharmaceutics \& Pharmacokinetics. Totowa, NJ: McGraw-Hill Medical; 2012:565-610.

14. Buitrago E, Hocht C, Chantada G, et al. Pharmacokinetic analysis of topotecan after intra-vitreal injection. Implications for retinoblastoma treatment. Exp Eye Res. 2010;91:9-14.

15. Qiu J, Gao H-Q, Liang Y, Yu H, Zhou RH. Comparative proteomics analysis reveals role of heat shock protein 60 in digoxin-induced toxicity in human endothelial cells. Biochim Biophys Acta. 2008;1784:1857-1864.

16. Piña Y, Decatur C, Murray TG, et al. Retinoblastoma treatment: utilization of the glycolytic inhibitor, 2-deoxy-2-fluoro-Dglucose (2-FG), to target the chemoresistant hypoxic regions in LHBETATAG retinal tumors. Invest Ophthalmol Vis Sci. 2012;53:996-1002.

17. Boutrid H, Piña Y, Cebulla CM, et al. Increased hypoxia following vessel targeting in a murine model of retinoblastoma. Invest Ophthalmol Vis Sci. 2009;50:5537-5543. 
18. Santana VM, Furman WL, Billups CA, et al. Improved response in high-risk neuroblastoma with protracted topotecan administration using a pharmacokinetically guided dosing approach. J Clin Oncol. 2005;23:4039-4047.

19. Pasquier E, Kieran MW, Sterba J, et al. Moving forward with metronomic chemotherapy: meeting report of the 2nd International Workshop on Metronomic and Anti-Angiogenic Chemotherapy in Paediatric Oncology. Transl Oncol. 2011;4: 203-211.

20. André N, Abed S, Orbach D, et al. Pilot study of a pediatric metronomic 4-drug regimen. Oncotarget. 2011;2:960-965.

21. Robison NJ, Campigotto F, Chi SN, et al. A phase II trial of a multi-agent oral antiangiogenic (metronomic) regimen in children with recurrent or progressive cancer. Pediatr Blood Cancer. 2014;61:636-642.

22. Pasquier E, Kavallaris M, André N. Metronomic chemotherapy: new rationale for new directions. Nat Rev Clin Oncol. 2010;7: 455-465.

23. Maiti R. Metronomic chemotherapy. J Pharmacol Pharmacother. 2014;5:186-192.

24. Malik PS, Raina V, André N. Metronomics as maintenance treatment in oncology: time for chemo-switch. Front Oncol. 2014;4:76.

25. Schaiquevich $\mathrm{P}$, Buitrago E, Taich $\mathrm{P}$, et al. Pharmacokinetic analysis of melphalan after superselective ophthalmic artery infusion in preclinical models and retinoblastoma patients. Invest Ophthalmol Vis Sci. 2012;53:4205-4212.

26. Mena HA, Lokajczyk A, Dizier B, et al. Acidic preconditioning improves the proangiogenic responses of endothelial colony forming cells. Angiogenesis. 2014;17:867-879.

27. Vezina M. Comparative ocular anatomy in commonly used laboratory animals. In: Weir A, Collins M, ed. Assessing Ocular Toxicology in Laboratory Animals. Los Angeles, CA: Humana Press; 2013:1-21.

28. Buitrago E, Del Sole MJ, Torbidoni A, et al. Ocular and systemic toxicity of intravitreal topotecan in rabbits for potential treatment of retinoblastoma. Exp Eye Res. 2013;108:103-109.
29. Varma MVS, Kapoor N, Sarkar M, Panchagnula R. Simultaneous determination of digoxin and permeability markers in rat in situ intestinal perfusion samples by RP-HPLC. J Chromatogr $B$ Analyt Technol Biomed Life Sci. 2004;813:347-352.

30. Jedlicka A, Grafnetterová, T, Miller V. HPLC method with UV detection for evaluation of digoxin tablet dissolution in acidic medium after solid-phase extraction. J Pharm Biomed Anal. 2003;33:109-115.

31. D'Argenio D. ADAPT II. User's Guide: Pharmacokinetic/ Pharmacodynamic Systems Analysis Software. 2006.

32. Riss TL, Moravec RA. Use of multiple assay endpoints to investigate the effects of incubation time, dose of toxin, and plating density in cell-based cytotoxicity assays. Assay Drug Dev Technol. 2004;2:51-62.

33. Francis JH, Abramson DH, Gaillard MC, et al. The classification of vitreous seeds in retinoblastoma and response to intravitreal melphalan [published online ahead of print March 18, 2015]. Ophthalmology. doi:10.1016/j.ophtha.2015.01.017.

34. Rössler J, Dietrich T, Pavlakovic H, et al. Higher vessel densities in retinoblastoma with local invasive growth and metastasis. Am J Pathol. 2004;164:391-404.

35. Rosenblatt MI, Azar DT. Anti-angiogenic therapy: prospects for treatment of ocular tumors. Semin Ophthalmol. 2006;21:151160.

36. Hillen F, Melotte V, van Beinum JP, Griffioen AW. Endothelial cell biology. In: Staton CA, Lewis C, Bicknell R, eds. Angiogenesis Assays: A Critical Appraisal of Current Techniques. Chichester, UK: John Wiley \& Sons; 2007:66-67.

37. Moschetta M, Mishima M, Sahin I, et al. Role of endothelial progenitor cells in cancer progression. Biochim Biophys Acta. 2014;1846:26-39.

38. Mesri M, Birse $\mathrm{C}$, Heidbrink $\mathrm{J}$, et al. Identification and characterization of angiogenesis targets through proteomic profiling of endothelial cells in human cancer tissues. PLoS One. 2013;11:e7885.

39. Svensson A, Azarbayjani F, Bäckman U, Matsumoto T, Christofferson R. Digoxin inhibits neuroblastoma tumor growth in mice. Anticancer Res. 2005;25:207-212. 